\section{Nephrology}

\author{
Walter Pfaller ${ }^{\mathrm{a}}$ \\ Thomas Seppi $i^{\text {a }}$ \\ Akihiro Ohno ${ }^{\mathrm{b}}$ \\ Gerhard Giebisch ${ }^{\mathrm{c}}$ \\ Franz X. Beck ${ }^{\mathrm{d}}$
}

a Institute of Physiology, University of Innsbruck, Austria;

b Department of Medicine, Kidney Centre, Tokyo Women's Medical College, Tokyo, Japan;

c Department of Cellular and Molecular Physiology, Yale University School of Medicine, New Haven, Conn., USA;

${ }^{d}$ Institute of Physiology, University of Munich, Germany

\section{Key Words}

Unilateral nephrectomy

Compensatory hypertrophy

Stereology

Renal hypertrophy

Renal hyperplasia

Nephron segments

$\mathrm{X}$-ray microanalysis

\title{
Quantitative Morphology of Renal Cortical Structures during Compensatory Hypertrophy
}

\begin{abstract}
The compensatory hypertrophy in different renal cortical structures was studied in rats 10 and 21 days after unilateral nephrectomy (UNX). Quantitative morphological/stereological analysis revealed significant increases in total renal cortical volume $-33 \%$ on day 10 and $48 \%$ on day 21 -after UNX. These changes were paralleled by significant increments in the volumes of proximal convoluted tubule (PCT, 55\%), distal convoluted tubule (DCT, 114\%), and cortical collecting duct (CCD, 106\%) segments on day 10 . The corresponding changes on day 21 were 76,122 , and $212 \%$, respectively. These alterations were accompanied by increases in segment length; 3\% PCT, 23\% DCT, and $50 \%$ CCD on day 10 and $9 \%$ PCT, 30\% DCT, and $142 \%$ CCD on day 21 after UNX. The total luminal and basolateral cell membrane surface areas also exhibited a time-dependent increase after UNX. The increments in both luminal and basolateral membrane domains in PCT and DCT after 10 days were not significant, but reached significance after 21 days (PCT: luminal membrane $21 \%$, basolateral membrane $63 \%$; DCT: luminal membrane $98 \%$, basolateral membrane $63 \%$ ). In contrast, CCD membrane areas had increased substantially already 10 days after UNX (luminal membrane $92 \%$, basolateral membrane $71 \%$ ). It declined subsequently by day 21 (luminal membrane $57 \%$, basolateral membrane $32 \%$ ). The cell rubidium concentration after a 30 -second rubidium infusion, an index of Na-K-ATPase activity, as well as sodium concentrations were unaltered in cells of all nephron segments investigated. Altogether the stereological analysis shows that the compensatory increase in organ volume can be attributed primarily to an increase in nephron epithelial volume. The PCT responds with 'radial' hypertrophy (thickening of the tubular epithelial wall), while the DCT undergoes 'length' hypertrophy (increase of tubular length without thickening of the tubular wall and without an increase in number of cells). This type of hypertrophy is especially prominent on day 21 after UNX for the CCD which doubles in length. Only on day 10 does the CCD seem to respond with hyperplasia. Adaptive changes in response to UNX develop gradually. Only a few of the morphological parameters studied had completed their change by 10 days, the majority required longer.
\end{abstract}

\begin{tabular}{ll}
\hline KARGER & (1) 1998 S. Karger AG, Basel \\
Fax +4161306 1234 & 1018-7782/98/0064-0308\$15.00/0 \\
$\begin{array}{l}\text { E-Mail karger@karger.ch } \\
\text { www.karger.com }\end{array}$ & $\begin{array}{l}\text { Accessible online at: } \\
\text { http://BioMedNet.com/karger }\end{array}$
\end{tabular}

Prof. Walter Pfaller, MD

Institute of Physiology, University of Innsbruck

Fritz-Pregl-Strasse 3, A-6010 Innsbruck (Austria)

Tel. +43(512) 507 3759, Fax, +43(512) 5072875 or 2853

E-Mail Walter Pfaller@uibk.ac.at 


\section{Introduction}

Loss of renal tissue or unilateral nephrectomy (UNX) results in a variety of functional and morphological adaptive responses in the remaining tissue. The most prominent response after UNX is an increase in the size of the remaining kidney due to hypertrophy, and hyperplasia of glomerular [1] and tubular [2, 3] components. This adaptive process is associated with hyperfiltration and increased transport capacity of the nephron epithelia.

There is general agreement that, at least in adult animals, the number of nephrons does not increase and that the rise in filtration rate is solely due to an increased single-nephron glomerular filtration rate (SNGFR) $[4,5]$. This adaptive response appears to be similar in cortical and juxtamedullary nephrons [6, 7]. Renal blood flow and GFR after UNX increase in parallel and are accompanied by increased glomerular volume and glomerular filtration surface area [1]. In addition, marked morphological changes occur in several tubule structures: hypertrophy and possibly hyperplasia in proximal tubular segments, increase in their protein content [8,9], enlargement of $\mathrm{Na}-$ K-ATPase-bearing basolateral membrane surfaces, and increases in volume of the mitochondrial compartment. Morphological changes in the distal nephron and the collecting duct are less pronounced than in proximal nephron segments $[2,10]$.

Most studies on quantitative morphological changes in the remnant kidney have been performed at a single interval after UNX and have focused mainly on the glomerulus and the proximal nephron. For instance, quantitative morphological changes as a function of time have been described only for selected glomerular and proximal tubular structural parameters [1], and in that study examination of the proximal tubule was restricted to determination of tubular diameter and length; transport-related ultrastructural parameters were not assessed. For distal convoluted tubule (DCT) and cortical collecting duct (CCD) - the two major distal nephron segments contained in the renal cortex - studies on time-dependent morphological changes after UNX have not been published.

The aim of the present investigation was thus to carry out a stereological analysis of the most relevant structural components of the rat renal cortex 10 and 21 days after UNX. This analysis was complemented by the measurements of several transport-related renal functions.

\section{Materials and Methods}

All experiments were performed on male Wistar rats with an average body weight of $254 \pm(\mathrm{SEM}) 5 \mathrm{~g}$. Animals were fed a standard chow (C1000 Altromin, Germany; $173 \mathrm{~g}$ protein $/ \mathrm{kg}$ diet) and allowed tap water ad libitum. UNX as well as sham surgery were carried out as described recently [11]. Renal clearance studies in situ, electron microprobe, and quantitative morphological stereological analyses were performed 10 and 21 days after UNX or sham surgery.

\section{Clearance Experiments}

Six animals per experimental group (sham, UNX 10 and UNX 21) were anesthetized with Inactin (Byk-Gulden, Konstanz, Germany) and placed on a thermostatically controlled surgical table. Following tracheotomy, right jugular vein and left femoral artery were cannulated for infusion of saline, monitoring of arterial blood pressure, and collection of blood samples. For determination of the leftkidney function, isotonic saline containing $2.5 \mathrm{~g} / 100 \mathrm{ml}$ polyfructosan (Laevosan, Linz, Austria) was administered at a rate of $10 \mathrm{ml} /$ $\mathrm{h} / \mathrm{kg}$. The left kidney was exposed via a flank incision, placed in a cup, and covered with warmed $\left(38^{\circ} \mathrm{C}\right)$ paraffin oil. Timed urine collections were obtained from a ureteral catheter. Arterial blood samples were taken at the beginning and at the end of several urine collection periods. After completion of clearance measurements, the kidney surface was cleaned by rinsing with prewarmed saline, and rubidium chloride $(0.5 \mathrm{mmol} / \mathrm{kg})$ was infused into the left femoral vein over a period of $30 \mathrm{~s}$. The kidney was removed immediately following the rubidum-containing infusion and frozen in a 3:1 propane:isopentane mixture kept at $-196^{\circ} \mathrm{C}$ by liquid nitrogen $[12,13]$.

\section{Element Concentrations}

Frozen sections $(1 \mu \mathrm{m})$ were taken from small pieces of the kidney cortex at $-90^{\circ} \mathrm{C}$ using a cryoultramicrotome (Ultrotome $\mathrm{V}$, LKB, Stockholm, Sweden). Cryosections were sandwiched between collodium and Formvar films, freeze-dried for $12 \mathrm{~h}$ at $-80^{\circ} \mathrm{C}$ at a pressure of $10^{-6} \mathrm{mbar}$, warmed to $40^{\circ} \mathrm{C}$, transferred rapidly to a scanning transmission microscope (DMS 950, Zeiss, Germany), and submitted to X-ray microanalysis using an energy-dispersive system (Link Systems, High Wycombe, UK). Measurements were performed at an acceleration voltage of $20 \mathrm{kV}$ and a probe current of $0.3 \mathrm{nA}$. Small areas $\left(1-2 \mu \mathrm{m}^{2}\right)$ were scanned for $100 \mathrm{~s}$ and the emitted $\mathrm{X}$-rays analyzed in the energy range of $0.2-20 \mathrm{keV}$. Measurements were restricted to the cell nucleus in order to avoid 'contamination' by basolateral infoldings and apical vesicles with electrolyte concentrations differing from cyto- and nucleosol $[14,15]$.

\section{Preparation for Stereological Analysis}

Kidneys were prepared as for clearance studies except that the femoral vessels were not catheterized and that the kidney was approached by median rather than by a flank incision. The kidneys were then cleared from blood by retrograde perfusion with Tyrode's solution ( $\mathrm{pH} \mathrm{7.4)} \mathrm{via} \mathrm{the} \mathrm{abdominal} \mathrm{aorta} \mathrm{at} 100 \mathrm{~mm} \mathrm{Hg}$ and $37^{\circ} \mathrm{C}$ for $30 \mathrm{~s}$ and subsequently perfusion fixed for $10 \mathrm{~min}$ with $1 \%$ glutaraldehyde buffered with Tyrode's solution ( $\mathrm{pH} 7.4,300$ mosm/l). Kidneys were removed and their total volume determined by displacement in the fixation solution using a graded measuring cylinder [16].

Exp Nephrol 1998;6:308-319 309 
Table 1. Renal functional parameters $($ mean \pm SEM)

\begin{tabular}{lccc}
\hline & Sham controls & UNX 10 days & UNX 21 days $^{\mathrm{a}}$ \\
\hline Body weight, g & $249 \pm 3$ & $256 \pm 6$ & $258 \pm 6$ \\
Mean arterial pressure, $\mathrm{mm} \mathrm{Hg}$ & $103 \pm 2$ & $98 \pm 2$ & $102 \pm 3$ \\
Hematocrit, \% & $46 \pm 1$ & $45 \pm 1$ & $48 \pm 1$ \\
Plasma Na, mmol/1 & $139.4 \pm 0.7$ & $139.8 \pm 1.0$ & $141.0 \pm 0.7$ \\
Plasma K, $\mathrm{mmol} / \mathrm{l}$ & $4.6 \pm 0.1$ & $4.5 \pm 0.1$ & $4.4 \pm 0.1$ \\
Urine flow, $\mu \mathrm{l} / \mathrm{min} / 100 \mathrm{~g}$ body weight & $1.1 \pm 0.1$ & $2.4 \pm 0.3^{* *}$ & $1.7 \pm 0.1^{* *}$ \\
GFR, $\mathrm{ml} / \mathrm{min} / 100 \mathrm{~g}$ & $0.52 \pm 0.02$ & $0.63 \pm 0.03^{* *}$ & $0.68 \pm 0.3^{* *}$ \\
Na-excretion, $\mathrm{nmol} / \mathrm{min} / 100 \mathrm{~g}$ & $26 \pm 8$ & $70 \pm 21^{*}$ & $61 \pm 19^{*}$ \\
$\mathrm{~K}-\mathrm{excretion}, \mathrm{nmol} / \mathrm{min} / 100 \mathrm{~g}$ & $360 \pm 28$ & $722 \pm 40^{* *}$ & $495 \pm 42^{*}$ \\
$\mathrm{FE}_{\mathrm{Na}}, \%$ & $0.03 \pm 0.01$ & $0.08 \pm 0.03^{*}$ & $0.06 \pm 0.02$ \\
$\mathrm{FE}_{\mathrm{K}}, \%$ & $15.0 \pm 1.1$ & $25.7 \pm 1.7^{* *}$ & $17.1 \pm 1.6$ \\
\hline
\end{tabular}

Significant differences from control: $* \mathrm{p}<0.05 ; * * \mathrm{p}<0.01$.

a Taken from Ohno et al. [11].

\section{Sampling for Stereological Analyses}

The fixed organs of 6 animals per experimental group were cut into five equidistant 3-mm slabs, and special care was taken that the slabs were randomly positioned with respect to the organ's long axis. Every slab was preceded by a $0.5-$ to $0.7-\mathrm{mm}$ slice. The slabs were processed conventionally for light microscopy and embedded in Paraplast. The slices were processed for electron microscopy using postfixation in $1 \%$ osmium tetroxide, dehydration in acetone, and embedding in Durcupan ACM (Fluka, Buchs, Switzerland). From every slab prepared for light microscopy, a $2-\mu \mathrm{m}$ section was taken and stained with hematoxylin and eosin. From each of these sections, the areal fractions, reflecting zonal volumes $\left(\mathrm{V}_{\mathrm{v} \text { zone }}\right)$ of cortex, outer stripe of outer medulla, inner stripe of outer medulla, and inner medulla were determined using a camera lucida equipped microscope and a digitizing tablet. The areal measures taken are directly proportional to the respective zonal volumes later used as reference values for the stereological parameters determined from tissue specimen processed for electron microscopy [16]. The absolute volume of zones was calculated as:

$$
\mathrm{V}_{\text {zone }}=\mathrm{V}_{\mathrm{V} \text { zone }} \times \mathrm{V}_{\text {kidney }}
$$

From the tissue specimens processed for electron microscopy, $0.5-\mu \mathrm{m}$ sections were taken from at least six blocks per animal. Renal cortical volume densities $\left(\mathrm{V}_{\mathrm{V}}\right)$ of the epithelium of proximal, distal and collecting duct segments, of the respective luminal or urinary space, as well as of glomeruli and interstitial and vascular spaces $\left(\mathrm{V}_{\mathrm{Vi}}\right)$ were determined under light microscopy at a strictly controlled magnification of $\times 1,200$. For collecting duct epithelium, the volume densities of principal cells (PC) and intercalated cells (IC) were separately assessed. Estimates of the respective volume densities were then referred to the total volumes of the kidney cortices in order to obtain absolute volumes $\left(\mathrm{V}_{\mathrm{i}}\right)$ for the respective tissue compartments:

$$
\mathrm{V}_{\mathrm{i}}=\mathrm{V}_{\mathrm{Vi}} \times \mathrm{V}_{\text {zone }}
$$

Since the one-dimensional structure, the virtual tubule axis, can be attributed to every cross-sectioned tubule profile, the number of penetrations of tubule axes per unit area of the planar probes (tissue sections of the renal cortex) can be assessed. The number of penetration points $\left(\mathrm{N}_{\mathrm{Ai}}\right)$ is directly proportional to the axial or tubular length per unit volume of tissue $\left(\mathrm{L}_{V}\right)$. Accordingly, the length density per unit volume of tissue can be given as:

$$
\mathrm{L}_{\mathrm{Vi}}=2 \mathrm{~N}_{\mathrm{Ai}}
$$

The absolute length of cortical nephron segments per kidney cortex can be determined from the absolute volume of the renal cortex, derived from the total organ volume and measured by displacement, and the respective zonal fraction, assessed on random sections through the kidney perpendicular to the organ's long axis (slabs, see above) [16, 17], as:

$$
\mathrm{L}_{\mathrm{i}}=\mathrm{L}_{\mathrm{Vi}} \times \mathrm{V}_{\text {zone }}
$$

Under electron microscopic magnification, assessments were made of surface densities $\left(\mathrm{S}_{\mathrm{V}}\right)$ of the luminal and basolateral plasma membrane of proximal, distal, and collecting duct segments, differentiated into PC and IC cells, in the renal cortex [16]. Absolute surfaces were calculated in analogy to absolute volumes. By relating $\mathrm{S}_{\mathrm{V}}$ and $\mathrm{L}_{V}$ estimates to each other, surface areas per unit length of nephron segments were obtained.

Determination of volume and surface density was performed on photographic negatives, projected onto a translucent screen [16], at a final magnification of $\times 5,000$ (luminal membrane surfaces) or $\times 10,000$ (basolateral membrane surfaces) by the point and intercept counting method [17] using a square lattice with a spacing of $\mathrm{d}=$ $0.51 \mu \mathrm{m}$ and $\mathrm{d}=0.28 \mu \mathrm{m}$, respectively.

In addition to stereological parameters, several morphometrical parameters, such as total and mean cross-sectional areas (A) of proximal convoluted tubule (PCT), DCT, and CCD transection profiles as well as a number of transected nuclei $\left(\mathrm{N}_{\mathrm{A}}\right)$ within these profiles, have been assessed.

\section{Statisticals}

The cell element concentrations and the cell dry weights are presented as mean values \pm SEM. The mean intracellular concentration of individual elements (sodium or rubidium), obtained in a specific tubule cell type in one kidney, was taken as a single observation and 
Table 2. Intracellular sodium and rubidium concentrations ( $\mathrm{mmol} / \mathrm{kg}$ wet weight; mean $\pm \mathrm{SEM}$ )

\begin{tabular}{|c|c|c|c|c|c|c|}
\hline & \multicolumn{2}{|c|}{ Sham controls } & \multicolumn{2}{|c|}{ UNX 10 days } & \multicolumn{2}{|c|}{ UNX 21 days $^{\mathrm{a}}$} \\
\hline & $\mathrm{Na}$ & $\mathrm{Rb}$ & $\mathrm{Na}$ & $\mathrm{Rb}$ & $\mathrm{Na}$ & $\mathrm{Rb}$ \\
\hline PCT & $21.7 \pm 0.5$ & $21.8 \pm 1.2$ & $20.9 \pm 1.2$ & $22.3 \pm 1.7$ & $21.2 \pm 0.7$ & $21.8 \pm 1.0$ \\
\hline DCT & $12.6 \pm 0.4$ & $49.5 \pm 4.1$ & $12.2 \pm 0.8$ & $53.6 \pm 6.7$ & $11.2 \pm 0.5$ & $48.7 \pm 3.0$ \\
\hline CCD PC & $12.7 \pm 0.7$ & $34.1 \pm 2.6$ & $10.8 \pm 1.4$ & $37.1 \pm 2.6$ & $11.2 \pm 0.9$ & $36.3 \pm 1.9$ \\
\hline \multicolumn{7}{|l|}{ CCD IC } \\
\hline Type I (chloride rich) & $13.0 \pm 0.8$ & $4.4 \pm 0.3$ & $12.6 \pm 0.5$ & $4.5 \pm 0.4$ & $12.1 \pm 0.6$ & $4.0 \pm 0.2$ \\
\hline Type II (chloride poor) & $14.1 \pm 0.6$ & $4.0 \pm 0.2$ & $14.9 \pm 0.3$ & $4.1 \pm 0.3$ & $13.3 \pm 0.4$ & $3.9 \pm 0.3$ \\
\hline
\end{tabular}

used for statistical analysis. Analysis of the collated stereological measures was performed by using nonparametric one-way analysis of variance. Differences between the groups of treatment were assessed by the two-tailed rank sum test of Mann and Whitney [18] for significance. The criterion for statistically significant differences was set at $\mathrm{p}<0.05$.

\section{Results}

\section{Clearance Experiments}

The data on body weight, blood pressure, plasma electrolytes, and gross renal function are summarized in table 1. UNX had no influence on body weight, mean arterial pressure, hematocrit, or plasma sodium or potassium concentrations. The GFR, however, increased by $21 \% 10$ days and by $30 \% 21$ days after UNX. Urine flow had more than doubled 10 days after UNX and was still $54 \%$ above the control value 21 days after UNX. Accordingly, urinary excretions of sodium and potassium were significantly increased at both intervals after UNX. Again the increase was more pronounced at 10 days than at 21 days after UNX.

\section{X-Ray Microanalysis}

Intracellular sodium and rubidium concentrations were determined in PCT and DCT cells as well as in PC and IC of the collecting duct. IC were divided further into groups with high or low intracellular chloride concentrations (chloride-rich and chloride-poor cells). Intracellular rubidium concentrations measured after a 30 -second rubidium infusion served as an index of the Na-K-ATPase activity [12]. No significant changes in intracellular sodium or rubidium concentrations could be detected after UNX in any of the cell types examined (table 2).

Quantitative Morphology of Renal

Compensatory Hypertrophy

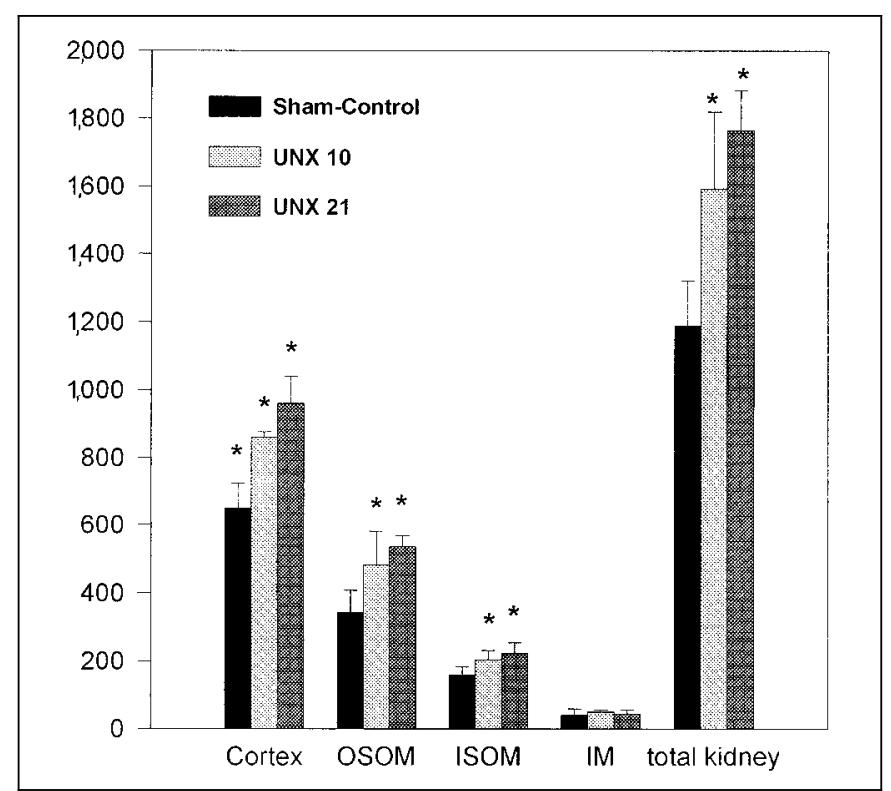

Fig. 1. Absolute volumes $(\mu \mathrm{l})$ of the major renal tissue zones following UNX. Data given are mean $\pm \mathrm{SD}$. Asterisks indicate significant differences from control $(\mathrm{p}<0.05)$. OSOM $=$ Outer stripe of outer medulla; ISOM = inner stripe of outer medulla, IM = inner medulla.

\section{Stereological Analysis}

Light Microscopy. No statistically significant differences in kidney weight were found 10 or 21 days after sham operation. For this reason the data were pooled and the group defined as sham controls. The volumes of the remaining kidneys following UNX were increased by 34 and $49 \%$ on days 10 and 21 , respectively. The increase in volume is confined to cortex, outer stripe of outer medulla, and inner stripe of outer medulla. No significant increase in inner medullary volume was detected (fig. 1).

Exp Nephrol 1998;6:308-319 311 
Fig. 2. Absolute volumes of luminal and epithelial compartments of the various nephron segments $(\mu \mathrm{l})$ contained in the renal cortex. The lower panel gives the estimates on CCD epithelium, and the contribution of the two morphologically discernible cell types on a larger scale than in the upper panel. Data given are mean $\pm \mathrm{SD}$. Asterisks indicate significant differences from control $(\mathrm{p}<0.05)$. PCT $=$ Proximal convoluted tubule; $\mathrm{DCT}=$ distal convoluted tubule; $\mathrm{CCD}$ = cortical collecting duct; GLOM = glomeruli (glomerular tuft and Bowman's capsule space); ECS = interstitial space; VS/CAP = vascular and capillary spaces.

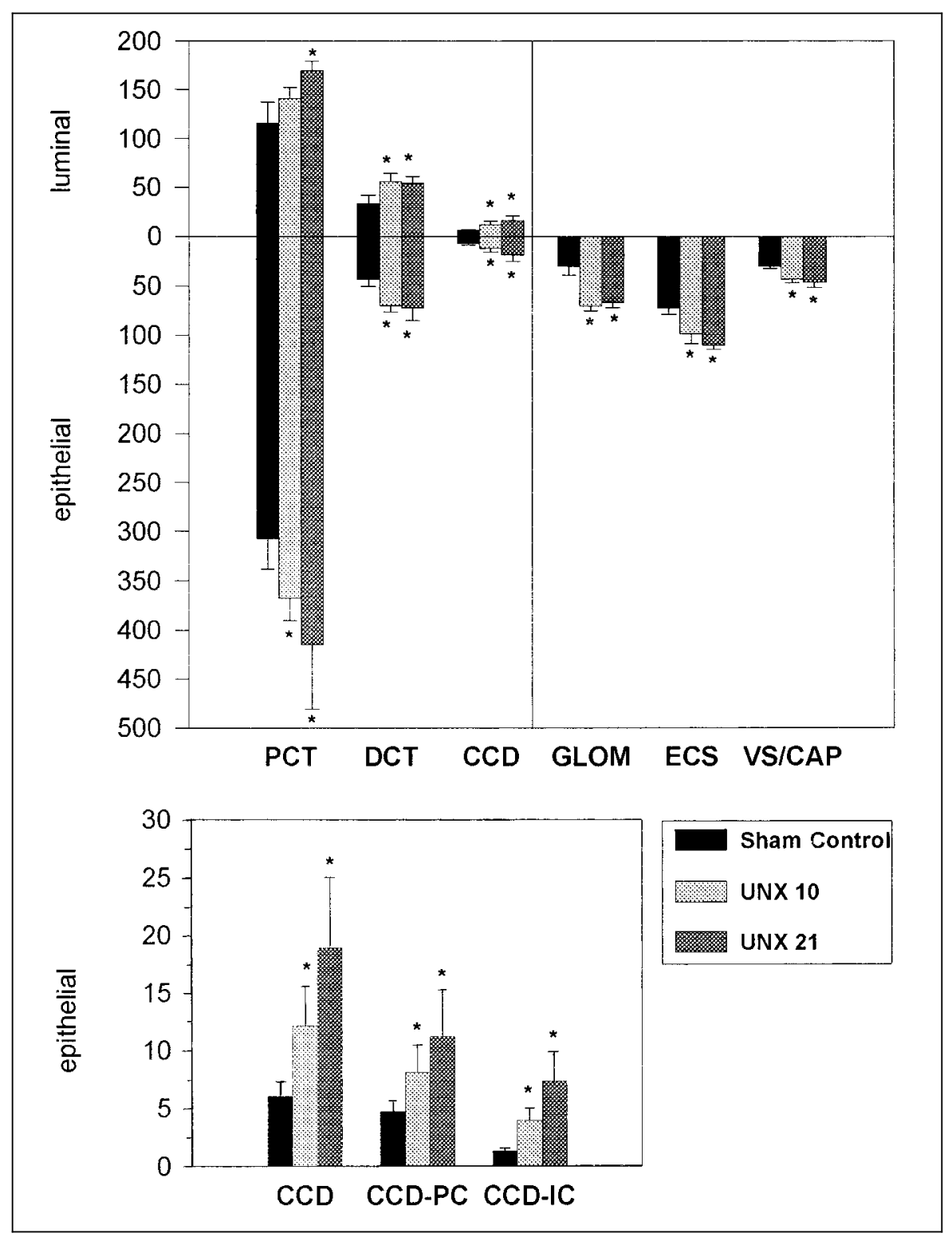

The contribution of the various tissue components to the volume increase was examined in detail for the renal cortex (fig. 2). An increase in volume of the nephron epithelium was the major factor contributing to the observed organ enlargement. In addition, a marked enlargement of the interstitial space and the total glomerular volume and of the vascular/capillary compartment also occurred (fig. 2). Whereas the increment in glomerular space appeared complete already 10 days after UNX, further enlargement of the volumes of the epithelial and urinary spaces continued from day 10 to day 21 after UNX.
Although the parameters usually employed to discriminate between hypertrophy and hyperplasia - the DNA/ protein ratio - were not assessed in this study, the determination of length of the nephron segments contained in the renal cortex indicates that hyperplasia may occur in parallel to hypertrophy. Interestingly, this response is most prominent in the CCD segment, followed by the DCT portion - it is least pronounced in the PCT (fig. 3). Similar to the augmentation of epithelial volume, the increase in nephron segment length gradually developed over the entire observation period (fig. 3) from day 10 to day 21 after UNX. 
Fig. 3. Total length of nephron segments contained in the renal cortex (m). Data given are mean $\pm \mathrm{SD}$. Asterisks indicate significant differences from control $(\mathrm{p}<0.05)$. $\mathrm{PCT}=$ Proximal convoluted tubule DCT $=$ distal convoluted tubule; $\mathrm{CCD}=$ cortical collecting duct.

Fig. 4. Absolute surface areas of the luminal and basolateral cell membrane domains contained in the renal cortex $\left(\mathrm{m}^{2}\right)$. The right half of the presentation gives the contribution of principal (PC) and intercalated (IC) cell membrane surfaces to that determined for the total cortical collecting duct (CCD) epithelium (left panel half). Data given are mean $\pm \mathrm{SD}$. Asterisks indicate significant differences from control $(\mathrm{p}<$ 0.05). PCT $=$ Proximal convoluted tubule; $\mathrm{DCT}=$ distal convoluted tubule.
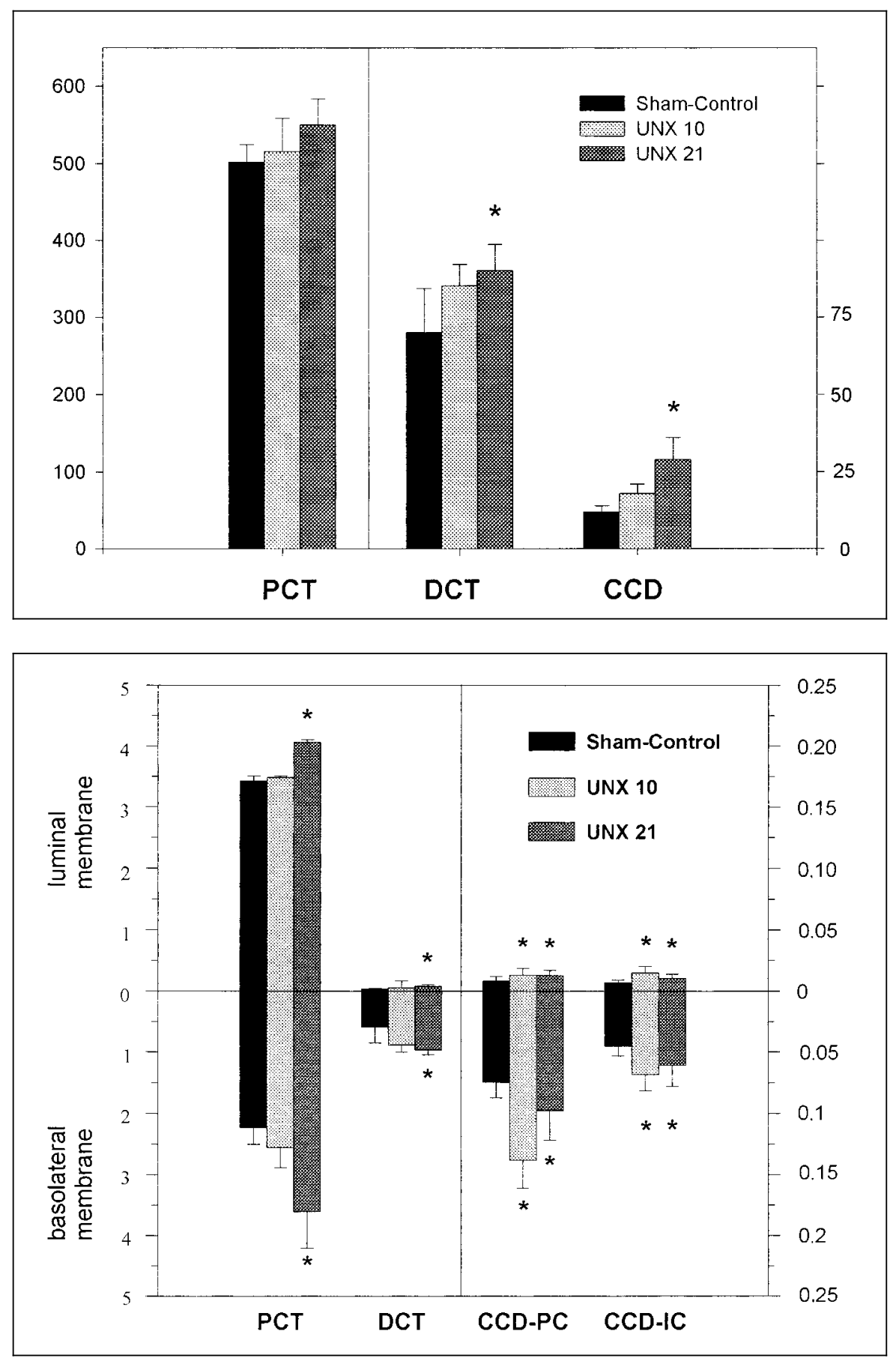

Electron Microscopy. We investigated the changes in luminal and basolateral membrane area, since these membranes are main determinants of transepithelial transport. The results are summarized in figure 4 . The total luminal membrane surface area of the PCT is nearly identical for the left kidney of sham controls and the remaining (origi- nally the left) kidney 10 days after UNX (fig. 4). However, 21 days after UNX a slight but significant increase was noted. The Na-K-ATPase-containing basolateral surface tended to increase $(+13 \%$, not significant) at 10 days and was markedly enlarged (+63\%) 21 days after UNX. If the absolute luminal and basolateral surface areas are re- 
Table 3. Surface $\left[\mathrm{S}_{\text {luminal and basolateral membrane }}\right]$ to volume $\left[\mathrm{V}_{\text {epithelium proximal, distal and collecting duct cells }}\right]$ ratio

\begin{tabular}{|c|c|c|c|c|c|c|}
\hline & \multicolumn{2}{|l|}{ Sham controls } & \multicolumn{2}{|l|}{ UNX 10 days } & \multicolumn{2}{|l|}{ UNX 21 days } \\
\hline & $\begin{array}{l}\text { S luminal/ } \\
\text { V epithelium }\end{array}$ & $\begin{array}{l}\mathrm{S} \text { basolateral/ } \\
\mathrm{V} \text { epithelium }\end{array}$ & $\begin{array}{l}\text { S luminal/ } \\
\text { V epithelium }\end{array}$ & $\begin{array}{l}\text { S basolateral/ } \\
\text { V epithelium }\end{array}$ & $\begin{array}{l}\text { S luminal/ } \\
\text { V epithelium }\end{array}$ & $\begin{array}{l}\text { S basolateral/ } \\
\text { V epithelium }\end{array}$ \\
\hline РCT, \% & 100 & 100 & 83 & 92 & 84 & 113 \\
\hline Mean & 0.01161 & 0.00791 & 0.00961 & 0.00726 & 0.00980 & 0.00896 \\
\hline $\mathrm{SD}$ & 0.00444 & 0.00343 & 0.00162 & 0.00242 & 0.00071 & 0.00302 \\
\hline$\%$ change & & & -17 & -8 & -16 & 13 \\
\hline DCT, $\%$ & 100 & 100 & 77 & 81 & 104 & 83 \\
\hline Mean & 0.00091 & 0.01644 & 0.00070 & 0.01399 & 0.00094 & 0.01364 \\
\hline $\mathrm{SD}$ & 0.00019 & 0.01103 & 0.00020 & 0.00424 & 0.00020 & 0.00274 \\
\hline$\%$ change & & & -23 & -19 & 4 & -17 \\
\hline CCD PC, $\%$ & 100 & 100 & 92 & 101 & 78 & 60 \\
\hline Mean & 0.00145 & 0.01566 & 0.00133 & 0.01586 & 0.00113 & 0.00932 \\
\hline $\mathrm{SD}$ & 0.00082 & 0.00831 & 0.00050 & 0.00471 & 0.00019 & 0.00272 \\
\hline$\%$ change & & & -8 & 1 & -22 & -41 \\
\hline CCD IC, $\%$ & 100 & 100 & 61 & 46 & 30 & 28 \\
\hline Mean & 0.00453 & 0.03181 & 0.00281 & 0.01480 & 0.00137 & 0.00902 \\
\hline $\mathrm{SD}$ & 0.00329 & 0.01451 & 0.00078 & 0.00336 & 0.00026 & 0.00327 \\
\hline$\%$ change & & & -38 & -53 & -70 & -72 \\
\hline CCD total, $\%$ & 100 & 100 & 86 & 79 & 57 & 47 \\
\hline Mean & 0.00214 & 0.01933 & 0.00184 & 0.01534 & 0.00121 & 0.00907 \\
\hline $\mathrm{SD}$ & 0.00123 & 0.00953 & 0.00036 & 0.00360 & 0.00021 & 0.00290 \\
\hline$\%$ change & & & -14 & -21 & -43 & -53 \\
\hline
\end{tabular}

ferred to the absolute volume of the proximal tubule, a 17 and $16 \%$ decline in the surface-to-volume (Slv) ratio can be found for the luminal membrane 10 and 21 days after UNX. The basolateral membrane-to-volume ratio is only slightly reduced after 10 days $(-8 \%)$, but remains unaltered or even marginally increased $(+13 \%)$ after 21 days (table 3).

The situation is different for the DCT. The absolute surface areas of both the luminal and basolateral membrane domains tend to increase 10 days after UNX and are increased significantly after 21 days (fig. 4). The S/V ratio is reduced for the luminal membrane in the 10-day group, but comparable to the controls in the 21-day group, whereas the basolateral $\mathrm{S} / \mathrm{V}$ ratio is diminished by 19 and $17 \%$. Accordingly, the volume increment exceeds the increment in basolateral membrane in that segment.

A significant increase in both absolute luminal and basolateral membrane surfaces can be observed in the CCD segment, although with a different time course. The membrane surface area enlargement was completed already 10 days after UNX (fig. 4). Calculations of the S/V ratios for the two cell types found in the cortical CCD segment indi- cate that for $\mathrm{PC}$ the luminal membrane $\mathrm{S} / \mathrm{V}$ ratio is marginally reduced $(-8 \%)$ after 10 days but displays an enhanced reduction (-22\%) 21 days after UNX. The basolateral S/V ratio is reduced markedly only on day 21 . In contrast, the IC display a substantial decrease in luminal and basolateral membrane-to-volume ratio on day 10 , which is further enhanced on day 21 after UNX (table 3).

From the directly assessed measures of surface density and length density we have calculated the surface areas of luminal and basolateral membrane domains per unit length $\left[\mathrm{S}_{\mathrm{L}}\left(\mathrm{mm}^{2} / \mathrm{mm}\right)\right]$ of the respective nephron segment, in order to be able to compare functional data obtained by micropuncture or related techniques with the morphological changes observed (fig. 5). Quite similar to the absolute surface area measures, the luminal surface per length in PCT increases, although the difference does not reach the level of significance. The $\mathrm{S}_{\mathrm{L}}$ of the distal luminal membrane displays a tendency towards an increase on day 21 after UNX. For basolateral surfaces per unit length a significant increase is given for the proximal tubule on day 21 after UNX. An increase is also found for the DCT basolateral membrane surface; again, however, the level 
Fig. 5. Absolute surface areas for luminal and basolateral membranes per unit length of nephron segment $\left(\mathrm{mm}^{2} / \mathrm{mm}\right)$. Data given are mean $\pm \mathrm{SD}$. Asterisks indicate significant differences from control $(\mathrm{p}<0.05)$. $\mathrm{PCT}=$ Proximal convoluted tubule; $\mathrm{DCT}=$ distal convoluted tubule; $\mathrm{CCD}=$ cortical collecting duct.

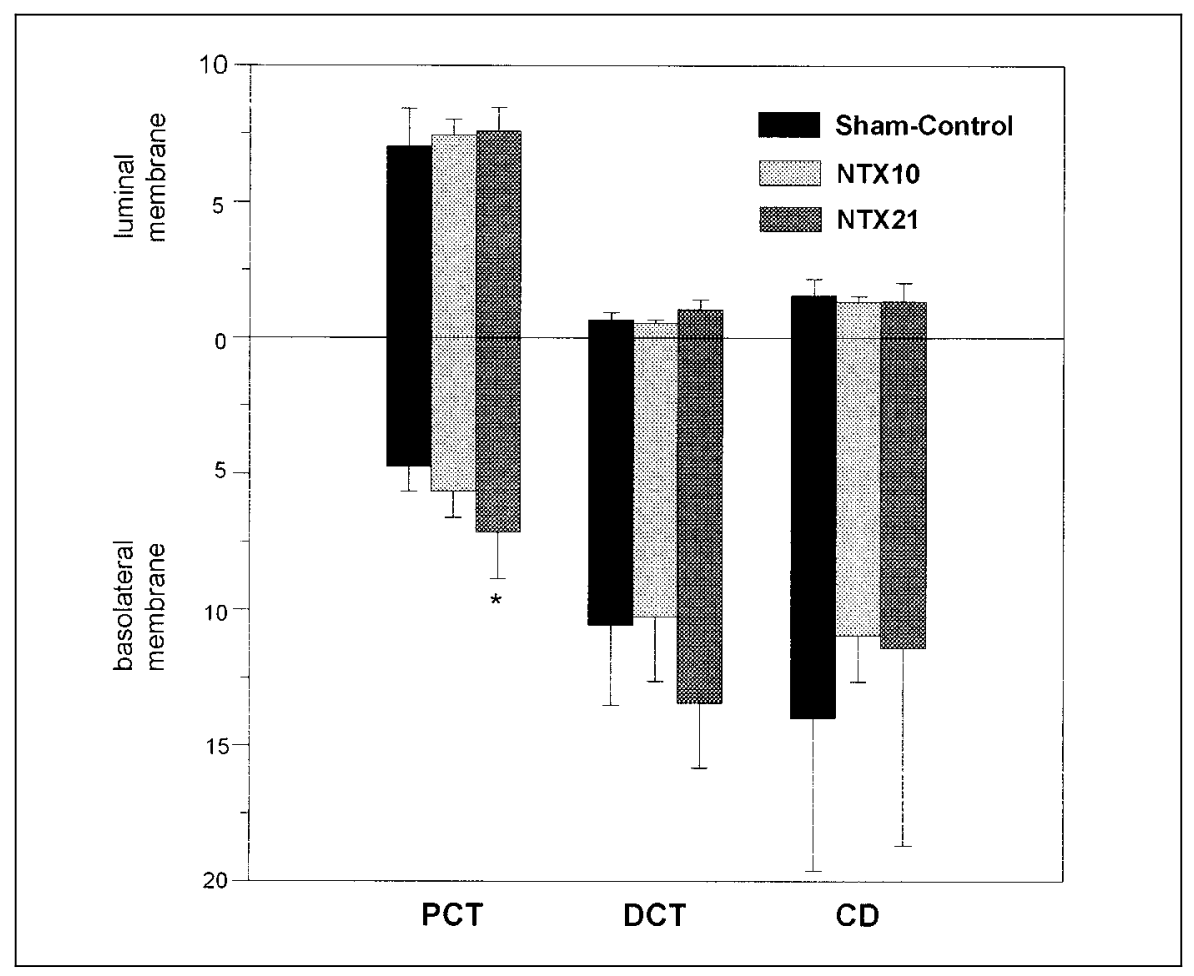

of significance is not achieved. Membrane surface areas along the collecting duct (there is no discrimination between the two major cell types possible) stay fairly constant over time after UNX and show a tendency towards a reduction in surface per length for the basolateral membrane domain (fig. 5) on both days 10 and 21 after UNX.

\section{Discussion}

The adaptive processes occurring after reduction in renal mass or unilateral nephrectomy have been the subject of numerous functional, biochemical, and morphological studies $[3,10]$. Whereas ample data are available on functional adaptation processes, the present investigation quantifies for the first time the morphological changes of the major cortical nephron segments at different intervals after UNX.

Changes in water and electrolyte handling by the contralateral kidney after UNX occur within minutes after UNX [19]. Overall excretion rates of solutes and water approach those of sham-operated controls rapidly. The GFR increases modestly but significantly as soon as $2-5 \mathrm{~h}$ after UNX, and this increment of GFR is associated with a decrease in fractional proximal tubule fluid and ion

Quantitative Morphology of Renal

Compensatory Hypertrophy reabsorption [19]. Reports on morphological changes of glomerular structures in this period are not available. The earliest time for which a morphological adaptation has been documented - an increase in kidney weight - is 12$14 \mathrm{~h}$ after UNX [19]. Coincident with such an increase in kidney weight is an increased reabsorption and a further elevation of the GFR [19]. In addition to enhanced $\mathrm{NaCl}$ reabsorption, the reabsorption of $\mathrm{HCO}_{3}^{-}$also is markedly stimulated by UNX. Maximal transport rates were doubled in the remnant kidney 21 days after UNX [11]. These functional adaptations are accompanied by an increase in proximal tubule epithelial volume on day 21 after UNX [11].

The present investigation extends these studies and was designed to examine the time course of morphological changes in renal cortical tissue during the compensatory adaptation of the remnant kidney. The results show changes not only in volume of nephron cells, but also in surface area of the cell membranes involved in transepithelial transport. According to the stereological analysis, several compartments within the renal cortex show already significant volume increases on day 10 after UNX (fig. 1) and, therefore, contribute to the increase in kidney weight. Interestingly, the increase in vascular/capillary, interstitial, and glomerular spaces, which are enlarged by

Exp Nephrol 1998;6:308-319 315 
roughly $30 \mu \mathrm{l}$ each, appears to be already complete on day 10. Seyer-Hansen et al. [1] have reported an increase in glomerular volume already 4 days after unilateral nephrectomy. so that this adaptation may be achieved early after UNX. The causes for these vascular volume changes may be related to the increase in renal blood flow developing after UNX [20, 21]. Since most of the functional changes described above precede morphological changes, it is reasonable to speculate that increments in glomerular, interstitial, and vascular/capillary spaces develop gradually as a consequence of the enhanced 'work load' in the remaining kidney. The present investigation further confirms earlier observations $[1-3,22]$ showing that the increase in renal tubular epithelial volume is the major cause for compensatory kidney enlargement (fig. 1). The epithelium of the PCT responds with a diameter enlargement, which is illustrated by the increased epithelial and urinary or luminal spaces (fig. 2). This implies an increase in the thickness of the PCT epithelial cell layer (fig. 2). Although not directly measured, this conclusion is compelling, since the total length of the PCT segments in the cortex is not markedly increased (fig. 3). This finding is in disagreement with the findings of Pollock et al. [21], who describe a 72\% increment in PCT length, but is in good agreement with the data of Seyer-Hansen et al. [1] which show a 15\% increase in PCT length 24 days after UNX. The discrepancy is probably due to the microdissection approach utilized by Pollock et al. [21].

The enlargement in PCT epithelial volume is accompanied by changes in the total luminal and basolateral membrane surface areas of the cortical tubule segments (fig. 4). Membrane area enlargement is less pronounced for the luminal than for the basolateral domain. When referring luminal and basolateral surface to a unit length of proximal tubule (fig. 5), the same pattern can be revealed. Although an increase in luminal membrane can be seen, it does not reach the level of significance. The basolateral membrane surface per unit length of nephron, however, is significantly increased on day 21 after UNX. Assuming that the transport kinetics of $\mathrm{H}^{+}$extruding carriers are not changed following UNX, the only slight enlargement of the luminal membrane surface would imply that the density of active $\mathrm{H}^{+}$carriers increases overproportionally, since the $\mathrm{V}_{\max }$ for $\mathrm{HCO}_{3}^{-}$reabsorption doubles 21 days after UNX [11]. The changes found for the PCT basolateral surface are similar to those reported by Salehmoghaddam et al. [23] who have quantified the changes in proximal tubular ultrastructure on tubular fragments isolated from the remaining kidney in rabbits 18-25 days after UNX. The surface increment in basola- teral membrane in the present investigation matches the increment in PCT epithelial volume. This follows from the unaltered basolateral membrane $\mathrm{S} / \mathrm{V}$ ratio (table 3 ). Although mitochondrial volume densities have not yet been determined in the present experimental model, an increment in this subcellular compartment can be assumed to occur as reported for PCT segments in the remnant rabbit kidney [23].

Adaptation of the distal convoluted nephron segment to UNX is also characterized by an increase in volume such that the increment reached after 10 days is nearly identical with that after 21 days. Different from the proximal nephron, the $\mathrm{S} / \mathrm{V}$ ratios, luminal surface area to distal epithelial volume, decrease initially (10 days after UNX, table 3 ) and return to control values 21 days after UNX. The basolateral $\mathrm{S} / \mathrm{V}$ ratio, in contrast, falls and remains low, indicating that the volume increase of distal tubular cells exceeds the increase of the basolateral, sodiumpumping membrane surface.

Morphological adaptation of collecting duct cells has a different time course. While the increase in epithelial volume develops gradually over time for both PC and IC (fig. 2), enlargement of luminal and basolateral membranes is fully developed already after 10 days and is most pronounced for the basolateral membrane of the $\mathrm{PC}$ at that time. Similar to the distal nephron segment, the CCD also responded with a gradual increase in length (fig. 3). On day 21 after UNX the segment length is more than doubled (fig. 3).

The resulting S/V ratios for PC luminal and basolateral membrane domains are comparable to the control values on day 10 after UNX. With respect to S/V ratios (table 3), a marked decrease is found for both luminal $(-20 \%)$ and basolateral $(-40 \%)$ domains on day 21 after UNX. If it is assumed that the decreased basolateral $\mathrm{S} / \mathrm{V}$ ratio is related to an equivalent change in PC sodium transport (at the single cell level), the sodium transport capacity of the whole CCD segment still may be significantly higher than in controls, since the length of this segment is doubled. The decreased $\mathrm{S} / \mathrm{V}$ ratios differ from data reported by Zalups et al. [24], showing a marked increase of this membrane in principal cells of the rat connecting tubule and CCD after substantial reduction in renal mass. This may be due to the fact that the latter data have been derived from a $75 \%$ nephrectomy model (i.e., 1.5 kidneys). Furthermore, a direct comparison of the morphometric measures is difficult, since the data reported for this $75 \%$ nephrectomy model are given as relative values, i.e., they have not been referred to the absolute volume of the CCD epithelium as in the present study. 
The $\mathrm{S} / \mathrm{V}$ ratios for both membrane domains of the IC are already reduced on day 10 after UNX. This cell type thus reacts with an overproportional increment in volume (table 3). In this context, the observations reported by Hamm et al. [25], namely that $\mathrm{HCO}_{3}^{-}$reabsorption per unit length of the $\mathrm{CCD}$, i.e., per millimeter of $\mathrm{CCD}$, tends to decrease after UNX, would be consistent with our quantitative morphological analysis. Since, however, the total CCD length and thereby the total surface area of luminal and basolateral membrane domains is substantially increased for both cell types forming the CCD, an increased transport capacity for $\mathrm{H}^{+}$and $\mathrm{HCO}_{3}^{-}$is likely to occur and would explain the observation that the remaining kidney is able to maintain acid-base homeostasis [25].

The data provided by the stereological analysis, especially the interrelation of absolute volumes and length of the various nephron segments, yield information on the extent to which hypertrophy or hyperplasia contributes to the increase in nephron epithelial volume.

Whether or not the respective segment undergoes hypertrophy or hyperplasia can be established from morphometric estimates of the cross-sectional area of the single proximal, distal, or collecting duct segment (including the tubular lumen) and the number of transected nuclei per nephron segment cross section in combination with the stereological estimates of segment lengths. Tubular hypertrophy can be distinguished from hyperplasia on the basis of the following relations:

If the square root of the ratio of the mean cross-sectional area $\left(\mathrm{A}_{\mathrm{Epi}}\right)$ of the respective nephron segments (PCT, $\mathrm{DCT}, \mathrm{CCD})$

$\sqrt{\mathrm{A}_{\text {Epi, PCT, DCT, CCD (UNX 10, 21)/A }} \text { Epi, PCT, DCT, CCD (sham control) }}$

is equal to the ratio of tubule segment lengths $(\mathrm{L})$

$\mathrm{L}_{\mathrm{PCT}}$, DCT, CCD (UNX)/ $\mathrm{L}_{\mathrm{PCT}}$, DCT, CCD (sham control)

and if in addition the ratio, mean number of nuclei $(\mathrm{N})$ per cross-sectioned area of tubular segments (PCT, DTC or $\mathrm{CCD}$ )

$\left.\mathrm{N}_{\mathrm{A}(\mathrm{UNX}} 10,21\right) / \mathrm{N}_{\mathrm{A}(\text { sham control) }}$

is smaller or equal to 1 , the observed increase in tubular volume represents hypertrophy and is solely due to an increase in cross-sectional radius or the thickness of the tubular wall of the cross-sectional profile.

If $\mathrm{N}_{\mathrm{A}}(\mathrm{UNX}) / \mathrm{N}_{\mathrm{A}}$ (sham controls) is larger than 1, i.e. there are more nuclei per transected epithelial area, hyperplasia has to be assumed. This is especially so if in addition the tubular segment increases in length.
If no increase in wall thickness can be found (no increased radius of transected profiles) and $\mathrm{N}_{\mathrm{A}}(\mathrm{UNX}) / \mathrm{N}_{\mathrm{A}}$ (sham controls) is close to 1 , but an increased segment length has been found, hyperplasia must be assumed. Hyperplasia is present also if the ratio $\mathrm{N}_{\mathrm{A}}(\mathrm{UNX}) / \mathrm{N}_{\mathrm{A}}$

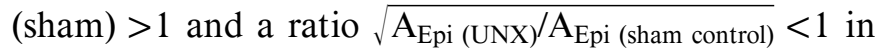
combination with a length ratio $>1$ is found. All these considerations are based on the assumption that every cell contains only one nucleus. The results of these considerations are summarized in table 4.

Ten days after UNX the proximal tubule wall crosssectional area, as well as that of the tubular lumen, increases, whereas the number of transectioned nuclei is reduced (table 4). This must be interpreted as hypertrophy due to radial enlargement of the tubular wall. The unchanged length of proximal tubules at this time further supports this conclusion. In the distal tubule we find an unchanged thickness of the cross-sectional area for the segment profiles but an increase in segment length in combination with a slight decrease in number of transected nuclei (table 4). This pattern implies a type of hypertrophy which changes tubular cell size and shape so that no increment in tubular wall thickness occurs ('length' hypertrophy). The CCD epithelial wall and lumen crosssectional area is unchanged, as is the number of nuclei (table 4). The segment length, however, is increased (fig. 3, table 4). Taken together this pattern points towards hyperplasia.

The situation 21 days after UNX shows for PCT a slight increase in length (fig. 3). The number of nuclei per PCT epithelium cross section, however, is diminished even more than on day 10 after UNX (table 4). These changes must be attributed to a further enhancement in PCT hypertrophy. The DCT length increment is markedly enlarged 21 days after UNX (fig. 3). Simultaneously we find an epithelial cross-sectional area and a number of transected nuclei smaller than on day 10 or in sham controls. These changes again imply hypertrophy of a type which changes cell size and volume so that tubules elongate without changing the wall thickness. For the CCD segment the above interpretation would appear to hold true. In contrast to the situation 10 days after UNX, we find an enormous 'length' hypertrophy. Since the number of transected nuclei is reduced roughly by half at an unchanged CCD cross-sectional area, the single-cell crosssectional area is more than doubled. If we assume that the number of cells along this nephron segment is not reduced, elongation of cells in the axial segment direction must be in the range of roughly $20 \%$. If the cell numbers decrease, which cannot be excluded, this axial elongation 
Table 4. Tubular similarity features

\begin{tabular}{|c|c|c|c|c|c|}
\hline & $\begin{array}{l}\text { Ratio of epithelial } \\
\text { volumes }\end{array}$ & $\begin{array}{l}\text { Ratio of epithelial } \\
\text { tansection areas }\end{array}$ & $\begin{array}{l}\text { Ratio of epithelial + } \\
\text { luminal transection } \\
\text { areas }\end{array}$ & $\begin{array}{l}\text { Absolute length of } \\
\text { nephron segment }\end{array}$ & $\begin{array}{l}\text { Numerical density } \\
\text { of nuclei }\end{array}$ \\
\hline & $\mathrm{V}_{\mathrm{UNX} 10} / \mathrm{V}_{\text {sham control }}$ & $\mathrm{A}_{\mathrm{UNX10}} / \mathrm{A}_{\text {sham control }}$ & $\mathrm{A}_{\mathrm{UNX10}} / \mathrm{A}_{\text {sham control }}$ & $\mathrm{L}_{\mathrm{UNX10}} / \mathrm{L}_{\text {sham control }}$ & $\begin{array}{l}\mathrm{N}_{\mathrm{ANuc}(\mathrm{UNX} 10)} / \\
\mathrm{N}_{\mathrm{ANuc}(\text { sham control) }}\end{array}$ \\
\hline \multirow{7}{*}{$\begin{array}{l}\text { PCT } \\
\mathrm{f}^{*} \\
\text { DCT } \\
\mathrm{f}^{*} \\
\text { CCD } \\
\mathrm{f}^{*}\end{array}$} & \multirow[t]{2}{*}{1.1951} & 1.2921 & 1.3007 & & \multirow{3}{*}{0.7500} \\
\hline & & 1.1367 & 1.1405 & \multirow[t]{2}{*}{1.0273} & \\
\hline & \multirow[t]{2}{*}{1.6174} & 0.9878 & 0.9961 & & \\
\hline & & 0.9939 & 0.9981 & \multirow[t]{2}{*}{1.2291} & \multirow[t]{3}{*}{0.7917} \\
\hline & \multirow[t]{2}{*}{1.6707} & 0.9830 & 1.0340 & & \\
\hline & & 0.9915 & 1.0168 & 1.5386 & \\
\hline & $\mathrm{V}_{\mathrm{UNX} 21} / \mathrm{V}_{\text {sham control }}$ & $\mathrm{A}_{\mathrm{UNX} 21} / \mathrm{A}_{\text {sham control }}$ & $\mathrm{A}_{\mathrm{UNX} 21} / \mathrm{A}_{\text {sham control }}$ & $\mathrm{L}_{\mathrm{UNX} 21} / \mathrm{L}_{\text {sham control }}$ & $\begin{array}{l}\mathrm{N}_{\mathrm{ANuc}(\mathrm{UNX} 21)} / \\
\mathrm{N}_{\mathrm{ANuc}(\text { sham control) }}\end{array}$ \\
\hline PCT & 1.3491 & 1.0842 & 1.1123 & & \\
\hline $\mathrm{f}^{*}$ & & 1.0412 & 1.0547 & 1.0962 & 0.4450 \\
\hline DCT & 1.6734 & 0.8519 & 0.8514 & & \\
\hline $\mathrm{f}^{*}$ & & 0.9230 & 0.9227 & 1.3765 & 0.4167 \\
\hline $\mathrm{CCD}$ & 2.5967 & 0.9920 & 0.9840 & & \\
\hline$f^{*}$ & & 0.9960 & 0.9919 & 2.4100 & 0.4333 \\
\hline
\end{tabular}

$f^{*} \sqrt{\mathrm{A}_{\mathrm{UNX10}} / \mathrm{A}_{\text {sham control }}}$ (linearized factor of change in the radius of the mean nephron segment cross-section profile) changes in length ratios can be compared to cross section area and volume ratios only when reduced to a one-dimensional scale. If this length scale is $\mathrm{L}: 1$, the surface ratios are $\mathrm{L}^{2}: 1$ and the volume ratios $\mathrm{L}^{3}: 1$ [Galileo Galilei 1638, cited from ref. 26].

must increase accordingly. Our data do not exclude that the cell number could be reduced by half at maximum (table 4). In this case the CCD single-cell cross-sectional area again more than doubles, but axial cell elongation would increase by $140 \%$ (table 4). The observed elongation of the CCD is accompanied by an enhanced cell turnover as mitoses, normally absent, can be observed regularly at both intervals after UNX. Unfortunately, the assessment of the exact cell number is not possible with the stereological sampling procedure utilised in the present study. Taken together, the data support the view that 21 days after UNX the CCD segment shows hypertrophy.

In none of the various tubule cell types examined were significant changes in intracellular $\mathrm{Rb}$ concentrations (measured after $30 \mathrm{~s}$ of the $\mathrm{Rb}$ infusion) or intracellular $\mathrm{Na}$ concentrations observed, either 10 or 21 days after UNX (table 2). The observation of unaltered intracellular $\mathrm{Rb}$ concentrations, however, does not necessarily infer unchanged $\mathrm{Rb}$ uptake. If, in a specific experimental condition, the cell volume is enlarged, the $\mathrm{Rb}$ uptake must increase proportionately to maintain intracellular $\mathrm{Rb}$ con- centrations. This implies that, in all tubule segments in which cell volume increases after unilateral nephrectomy, $\mathrm{Rb}$ uptake, i.e., the $\mathrm{Na}-\mathrm{K}(\mathrm{Rb})-\mathrm{ATPase}$ activity, increases in proportion to cell volume. Such an increase in Na-KATPase activity could be due, in principle, to an acceleration of the 'turnover' rate of the individual transporters and/or to an increase in the number of functioning NaK-ATPase molecules. Although the present results do not allow us to distinguish between these alternatives, a previous study [23] has shown that the $\mathrm{K}_{\mathrm{m}}$ value for ouabainsensitive potassium uptake in proximal tubule cells is not affected significantly by reduction of renal mass, while the $\mathrm{V}_{\max }$ value and the number of ouabain molecules specifically bound per cell are significantly elevated. These observations, and the fact that intracellular Na concentrations - a major determinant of the Na-K-ATPase turnover rate were unchanged, favor the notion that the rise in Na-K-ATPase activity following UNX is mostly due to an increase in the number of functioning transport molecules, a conclusion also attained by Salehmoghaddam et al. [23]. 
In summary, the present stereological analysis clearly shows that UNX leads to a differentiated response of the various nephron segments contained in the renal cortex. Whereas the proximal nephron undergoes predominantly 'radial' hypertrophy, with enlargement of tubular epithelial volume, the distal convoluted segment increases in both volume and length and, therefore, displays 'length hypertrophy. The CCD segment shows hyperplasia on day 10, but 'length' hypertrophy 21 days after UNX. These adaptive processes also affect glomerular, interstitial and vascular spaces of the renal cortex. Adaptation to UNX at the subcellular level is characterized by increases in absolute luminal and basolateral membrane surface areas. The time course of quantitative morphologic changes also differs in the different nephron segments. Whereas length in all segments continued to increase over the 21 days, this was true for epithelial volume only in the proximal nephron. The volume increase in the distal segments was already maximal within the first 10 days after UNX.

\section{Acknowledgments}

This work was supported by a grant from the Wilhelm SanderStiftung (91.009.1). The authors are indebted to Mrs. E. Nemati for technical assistance. We also thank Drs. G. Gstraunthaler and J. Davis for their critical comments.

\section{References}

1 Seyer-Hansen K, Gundersen HJG, Osterby R: Stereology of the rat kidney during compensatory renal hypertrophy. Acta Pathol Microbiol Immunol Scand [A] 1985;93:9.

2 Hayslett JP, Kashgarian M, Epstein FH: Functional correlates of compensatory renal hypertrophy. J Clin Invest 1968;47:774.

3 Wesson LG: Compensatory growth and other responses of the kidney. Nephron 1989;51: 149.

4 Deen WM, Maddox DA, Robertson CR, Brenner BM: Dynamics of glomerular ultrafiltration in the rat. VII. Response to reduced renal mass. Am J Physiol 1974;227:556.

5 Kaufman JM, Siegel NJ, Hayslett JP: Functional and hemodynamic adaptation to progressive renal ablation. Circ Res 1975;36:286.

6 Buerkert J, Martin D, Prasad J, Chambless S, Klahr S: Response of deep nephrons and the terminal collecting duct to a reduction in renal mass. Am J Physiol 1979;236:F454.

7 Pennel PJ, Bourgoignie JJ: Adaptive changes of juxtamedullary glomerular filtration in the remnant kidney. Pflügers Arch 1981;389:131

8 Fine LG, Trizna W, Bourgoignie JJ, Bricker NS: Functional profile of the isolated uremic nephron: Role of compensatory hypertrophy in the control of fluid reabsorption by the proximal straight tubule. J Clin Invest 1978;60: 1508.

9 Johnston JR, Brenner BM, Hebert SC: Uninephrectomy and dietary protein affect fluid absorption in rabbit proximal straight tubules. Am J Physiol 1987;253:F222.
10 Meyer TW, Keshwar B, Brenner BM: Nephron adaptation to injury; in Brenner BM (ed): The Kidney. Philadelphia, Saunders, 1996, vol II, pp 2011-2048.

11 Ohno A, Beck FX, Pfaller W, Giebisch G, Wang T: Effects of chronic hyperfiltration on proximal tubule bicarbonate transport and cell electrolytes. Kidney Int 1995;48:712.

12 Beck FX, Dörge A, Blümner E, Giebisch G, Thurau K: Cell rubidium uptake: A method for studying functional heterogeneity in the nephron. Kidney Int 1988;33:642.

13 Beck FX, Sone M, Dörge A, Thurau K: Effect of loop diuretics on organic osmolytes and cell electrolytes in the renal outer medulla. Kidney Int 1992;42:843.

14 Beck FX, Bauer R, Bauer U, Mason J, Dörge A Rick R, Thurau K: Electron microprobe analysis of intracellular elements in the rat kidney. Kidney Int 1980;17:756.

15 Beck FX, Dörge A, Rick R, Thurau K: Intraand extracellular element concentrations of rat renal papilla in antidiuresis. Kidney Int 1984; 25:397.

16 Pfaller W: Structure-function correlation on rat kidney. Adv Anat Embryol Cell Biol 1982; 70:1.

17 Weibel ER: Stereological Methods: Practical Methods for Biological Morphometry. London Academic Press, 1979, vol 1.

18 Sachs L: Angewandte Statistik: Anwendung statistischer Methoden, ed 6. Berlin, Springer, 1984.
19 Shirley DG, Walter SJ: Acute and chronic changes in renal function following unilateral nephrectomy. Kidney Int 1991;40:62.

20 Anderson S, Meyer TW, Rennke HG, Brenner BM: Control of glomerular hypertension limits glomerular injury in rats with reduced renal mass. J Clin Invest 1985;76:612.

21 Pollock CA, Bostrom TE, Dyne M, Györy AZ, Field MJ: Tubular sodium handling and tubuloglomerular feedback in compensatory renal hypertrophy. Pflügers Arch 1992;420:159166

22 Hostetter TH, Olson JL, Rennke HG, Venkatachalam MA, Brenner BM: Hyperfiltration in remnant nephrons: A potentially adverse response to renal ablation. Am J Physiol 1981; 241:F85.

23 Salehmoghaddam S, Bradley T, Mikhail N, Badie-Dezfooly B, Nord EP, Trizna W, Kheyfets R, Fine LG: Hypertrophy of basolateral Na-K pump activity in the proximal tubule of the remnant kidney. Lab Invest 1985;53:443.

24 Zalups RK, Stanton BA, Wade JB, Giebisch G: Structural adaptation in initial collecting tubule following reduction in renal mass. Kidney Int 1985;27:636.

25 Hamm LL, Hering-Smith KS, Vehaskari VM: Control of bicarbonate transport in collecting tubules from normal and remnant kidneys. Am J Physiol 1989;256:F680.

26 Astrand PO, Rodahl K: Textbook of Work Physiology: Physiological Bases of Exercise, ed 3. New York, McGraw-Hill, 1986. 